Acta Horticulturae et Regiotecturae 2

Nitra, Slovaca Universitas Agriculturae Nitriae, 2019, pp. 88-92

\title{
SOLUTION OF THE FOREST ROAD NETWORK OPTIMIZATION IN THE TRANSFORMATION TO A SELECTIVE SILVICULTURE METHOD
}

\author{
Jaromír SKOUPIL ${ }^{1 *}$, Petr PELIKÁN ${ }^{1}$, Jiří KADLEC ${ }^{2}$ \\ ${ }^{1}$ Mendel University in Brno, Czech Republic \\ ${ }^{2}$ SZIF RO Olomouc, Státní zemědělský intervenční fond, Regionální odbor Olomouc, Czech Republic
}

\begin{abstract}
The paper is focused on the forest road access in the area of supposed specific method of forest management. The studied forest area of 81 hectares (ha) is intended for transformation by selective silviculture method demanding dense forest road network. The parameters of the current road network were analysed by Beneš method based on quantifying the general geometric and configuration criteria of the road network. The new road distribution was designed with respect to the results of the terrain slope and runoff concentration analyses to reduce the negative impacts of the roads on the surrounding environment. The new road layout resulted to the decrement of all types of skidding distances. The real skidding distance Ds decreased by $51 \%$ to the value of $72 \mathrm{~m}$. In addition, the road network efficiency was increased by $14 \%$.
\end{abstract}

Keywords: road network efficiency, runoff concentration, slope analysis, timber skidding

The road network is an integral part of forest management and an important tool for forestry. Other forest management technologies depend on the road network. The forest road network should be designed to allow to choose the most optimal timber harvesting and concentration technology in the given conditions, meeting the requirements for high productivity, low cost and environment-friendly.

Accessing the forest during the transition to a selective silviculture method has certain specifics. The selective forest is created as a result of the application of the so-called selective forest management method. To put it simply, instead of the usual harvesting of trees of a certain age, the trees of the target thickness are regularly harvested, while at the same time aiming for the highest age and spatial diversity of such a forest achieved by "cultivation selection". Selective forests often originated from so-called "farmer forests" or municipal forests where the selection of timber needed for running the farm or community was used (Ammon, 2009). The contrast of thickness classes in the selected and clearcut forest is typical. While in the passive forest the thickness of the trees depicts a Gaussian curve, a typical declining curve (hyperbola) showing a decrease in abundance towards higher thickness classes is typical for the forest (most trees are in lower thickness classes and their number rapidly decreases towards the target thickness). The forest stand stock is evenly distributed over the entire forest area in a mixed group structure. An important feature is the sustained vertical canopy of trees (Ammon, 2009). The structure of the forest is similar to some temperate wildwood. In order to be able to manage a forest (tree felling and timberskidding), a sufficiently dense transport network is required to facilitate any tree to be cut down and transported. We distinguish two economic ways in a selective forest: individually selective and group selective. In the case of the individually selected management method, the individual "mature" trees are harvested according to the target thickness and thus the auspicious individuals are eased on the lower floors from the subjection of other trees. Trees are removed if it is economically favourable or phytopathologically necessary. Dead, diseased or withered trees are also removed. This method is convenient for shady (fir, beech) or shade-tolerant (spruce) woods (Polanský, 1966). Small-scale cultivation and felling operations take place in small-scale groups, which are convenient for sunny tolerant species. Due to age and spatial diversity, the selective forest is able to withstand harmful influences such as wind, snow or pests. Durability, safety and fluency (yield equilibrium) are secured on a much smaller area than other forest types (an area of 10 ha or less is stated).

It also allows small scale owners to receive regular yields without having to wait for rotation period. This way of management perfectly uses the soil and air space. Several tree layers attract and use an incident light better. Clearing is not necessary and the forest performs its non-production functions better and more permanently. Usually no artificial afforestation is needed (natural reproduction occurs spontaneously) (Polanský, 1966).

The selective forest management is demanding in terms of expertise and time of the forest manager. Timber harvesting and skidding is technologically more difficult, less centralized (scattered over a larger area), and therefore, may be more expensive. It requires perfect accessibility; therefore a dense transport network is a condition for successful management. The optimal skidding traces

Contact address: Ing. Jaromír Skoupil, Ph.D., Mendel University in Brno, Faculty of Horticulture, Department of Horticultural Machinery, Valtická 337, 69144 Lednice 
spacing in the selection forest is equal to the twofold height of the tree from the group of target thicknesses. Depending on the tree species and habitat, the spacing is about $50 \mathrm{~m}$. Directional felling is directed from the stand to the skidding trace to minimize damage of the surrounding trees in the stand. It is very important that the used forwarder is able to harmlessly move along the skidding trace, so it is advisable to design its width of $3.5-4 \mathrm{~m}$. It is also very important to consider slope conditions in the design of the road network to avoid excessive damage of the soil surface and subsequent erosion. Due to the character of the selective management and the individual selection, the predominant technology will be the use of a chainsaw and a tractor with a winch, or a forwarder with a winch for skidding the timber assortment from the stand to the trace and then skidding to the loading bay. The use of harvesters in timber extraction cannot be used because of the high extraction costs caused by scattered cutting and the different masses of timber on the harvested area.

The calculations of the road network parameters and related engineering tasks can be very time consuming, hence the geographical information systems are often used (Lotfalian, Zadeh and Hosseini, 2011). In recent years, LiDAR technology has also undergone great advances and shows applicability to forest management, becoming the source of high precision geometric data (Novo et al., 2019).

The aim of this work is to optimize the design process of forest road network. The use of geographic information systems make it possible to find suitable terrain with low water runoff concentration to minimize negative impacts in the construction of forest roads, such as erosion.

\section{Material and methods}

\section{Study area}

In order to evaluate the condition of the forest road network and to propose its optimization with the aim of transformation to a selective silvicultural management method, a site located in the cadastral area of Nový Hrozenkov (Vsetín District), which is a part of the protected landscape area Beskydy (Fig. 1), was selected. It is a forest area of 81 ha, managed by the Augustinian Abbey Forests. The boundary of the territory is formed by a reinforced haul road $1 \mathrm{~L}$ class in the north; the ridge is the southern border,

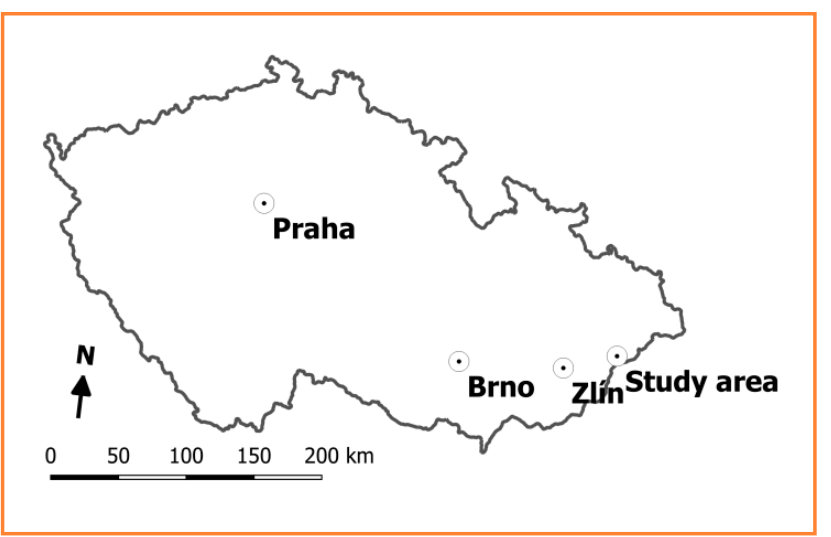

Figure 1 Localization of the study area which is also the state border with Slovakia. It is a difficult accessible locality due to the broken terrain ranging from 600 to $870 \mathrm{~m}$ above sea level. The average slope of the terrain is $33.8 \%$. There are only unpaved forest roads and skidding traces inside the territory.

\section{Road network evaluation}

Road networkwas evaluated by means ofBenešmethodology presented in 1986. The method was developed for forest haul road network assessment. The practical application consists of the road network distribution optimization within the various morphologic areas (flatlands, uplands and mountains). The methodology is based on quantifying the general geometric and configuration criteria of the road network.

The road density is often considered as the main criterion of the access. The density $H\left(m \cdot h a^{-1}\right)$ is given by equation

$$
H=\frac{D}{S}
$$

where:

$D$ - the total road network length $(\mathrm{m})$

$S$ - the accessed area (ha)

As the parameter does not provide any information on the road network distribution, the additional parameters are implemented (Hrůza, Pelikán and Hemr, 2019). The method deals with various types of distances representing the traces of timber transport from the point of harvesting to the haul road. The points of harvesting represent the centroids of squares orderly located in the grid within the accessed area. The original method assumes the particular square area of 10 ha. The 1 ha grid was used with regard to the special purpose of the method and total small study area.

The theoretic skidding distance $D_{t}(\mathrm{~m})$ is an average skidding distance due to the optimal distribution of roads in the accessed area and it depends on the road density $\mathrm{H}$ :

$$
D_{t}=\frac{10,000}{4 H}
$$

The geometric distance $D_{g}(\mathrm{~m})$ represents the direct distance from point of harvesting to the haul road (Beneš, 1986). The average value of $D_{g}$ depends on the road distribution and generally is higher than the theoretic skidding distance:

$$
\overline{D_{g}}=\frac{D_{g 1}+D_{g 2}+\ldots D_{g n}}{n}
$$

The real skidding distance $D_{s}(\mathrm{~m})$ was considered as the distance from point of harvesting measured along the fall line until crosses the trace of timber skidding, haul road or study area boundary:

$$
\overline{D_{s}}=\frac{D_{s 1}+D_{s 2}+\ldots D_{s n}}{n}
$$

In some cases, the correction factor of mean skidding distance is calculated from the division of real mean skidding 
distance by theoretical mean skidding distance (Lotfalian, Zadeh and Hosseini, 2011). We would rather focus on the road network efficiency in the study. The efficiency of the road network $U(\%)$ is finally calculated from the theoretic and average geometric distance:

$$
U=\frac{D_{t}}{\overline{D_{g}}} \cdot 100
$$

An important aspect is perfect knowledge of terrain configuration (Beneš, 1973). The analysis of road network parameters was performed in the open source geographic information system QGIS Desktop. The regular grid of points of harvesting and line shapefile of road network were used as the main input data. In addition, the data of the $5^{\text {th }}$ generation digital terrain model of the Czech Republic (DMR $5 \mathrm{G}$ ) in the text format were used for the digital elevation model creation (DEM). The geometric skidding distances from grid points to roads were performed by vector analysis tool Distance to nearest hub.

The analysis of skidding distances required the application of the set of tools. The data of DMR 5G were interpolated into the DEM with sink removal, flow direction, slope and flow accumulation analysis. The vector road network and points of harvesting grid were converted into the raster. The raster road network was burned into the DEM as a barrier; hence the Flow path length tool was performed to calculate real skidding distances. The other supporting calculations were processed in the MS Excel spreadsheet.

\section{Road network design}

To design routes of the forest road network three degrees of the ground slope were determined. Specification of the extent of slope intervals for particular degrees is based on the terrain classification prepared by Lesprojekt (1980). The classification is commonly used in forest practice and serves also for the so-called technological typification (Simanov, Macků and Popelka, 1993).

Degrees (Deg.) of the ground slope:

Deg. 1 - slope $0-25 \%$, areas of small slope, suitable for building the forest road network.

Deg. 2 - slope $26-40 \%$, areas of medium slope, less suitable for building the forest road network.

Deg. 3 - slope $>40 \%$, areas of high slope, unsuitable for building the forest road network.

The forest road network significantly influences the circulation of water in the area. It results in the increase of surface water runoff from the area and a related increase of soil erosion. A surface runoff concentration can be used as a further criterion for optimizing the forest transport network to reduce the negative effects on water outflow (Krešl, 1990). The study area was divided into three zones of runoff concentration. The threshold values are considered as the delimiting values of the particular modeled microcatchment areas in their outlet nodes.

Degrees (Deg.) from the aspect of runoff concentration:

Deg. 1 - areas with low concentration of runoff, suitable for building the road network (microcatchment area $<50 \mathrm{~m}^{2}$ )

Deg. 2 - areas with medium concentration of runoff, less suitable for building the forest road network (microcatchment area 50-150 $\mathrm{m}^{2}$ )

Deg. 3 - areas with high concentration of runoff, unsuitable for building the forest road network (microcatchment area $>150 \mathrm{~m}^{2}$ )

\section{Results and discussion}

\section{Actual road network parameters}

The actual total length of unbound roads is $6,090 \mathrm{~m}$ within the study area. The road network density reaches $75.2 \mathrm{~m} \cdot \mathrm{ha}^{-1}$ and average geometric distance $D_{g}$ is $53 \mathrm{~m}$. However, the average real skidding distance $D_{s}$ is $147 \mathrm{~m}$, the value can be considered too high for purposes of transformation to selective forest management. The theoretic distance $D_{t}$ is $33 \mathrm{~m}$ and the road network efficiency is $U=63 \%$. The results of the analysis show that the road layout is unbalanced because of too high average real skidding distance due to the quite low efficiency.

\section{Road network optimization}

In order to design the optimal road network layout, slope and runoff concentrations were performed. The raster outputs were reclassified in order with above-mentioned classification scale (degrees of suitability) as discussed in Skoupil (2006). The rasters were combined with the use of map algebra (summation of map layers) to the resulting map with delimitation of the three zones from the point of view of the design and building forest roads (Table 1, Fig. 2):

1 - areas suitable for building the forest road network

2 - areas less suitable for building the forest road network

3 - areas unsuitable for building the forest road network

Table 1 Area delimitation according to suitability for planning and building forest roads

\begin{tabular}{|c|c|c|c|c|}
\hline & & \multicolumn{3}{|c|}{ Surface runoff concentration } \\
\hline & & Deg. 1 low & Deg. 2 medium & Deg. 3 high \\
\hline \multirow{3}{*}{ 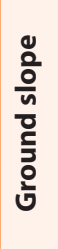 } & Deg. 1 low (0-25\%) & $\begin{array}{c}1 \\
(1+1=2)\end{array}$ & $\begin{array}{c}1 \\
(1+2=3)\end{array}$ & $\begin{array}{c}2 \\
(1+3=4)\end{array}$ \\
\hline & Deg. 2 medium (26-40\%) & $\begin{array}{c}1 \\
(2+1=3)\end{array}$ & $\begin{array}{c}2 \\
(2+2=4)\end{array}$ & $\begin{array}{c}3 \\
(2+3=5)\end{array}$ \\
\hline & Deg. 3 high (>40\%) & $\begin{array}{c}2 \\
(3+1=4)\end{array}$ & $\begin{array}{c}3 \\
(3+2=5)\end{array}$ & $\begin{array}{c}3 \\
(3+3=6)\end{array}$ \\
\hline
\end{tabular}




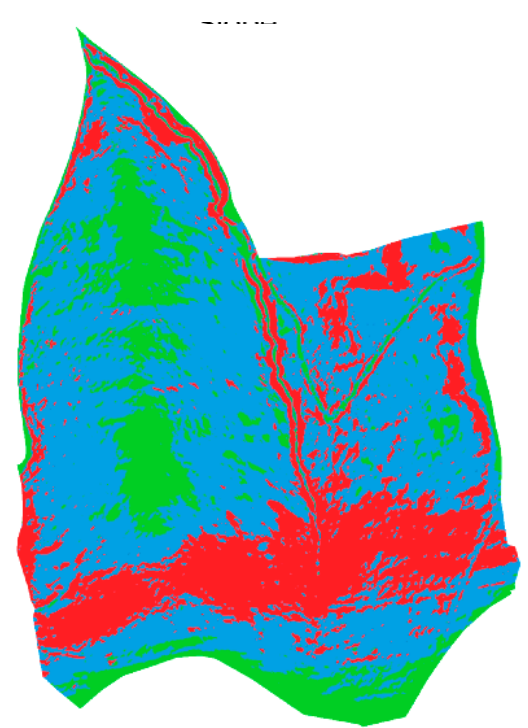

slope

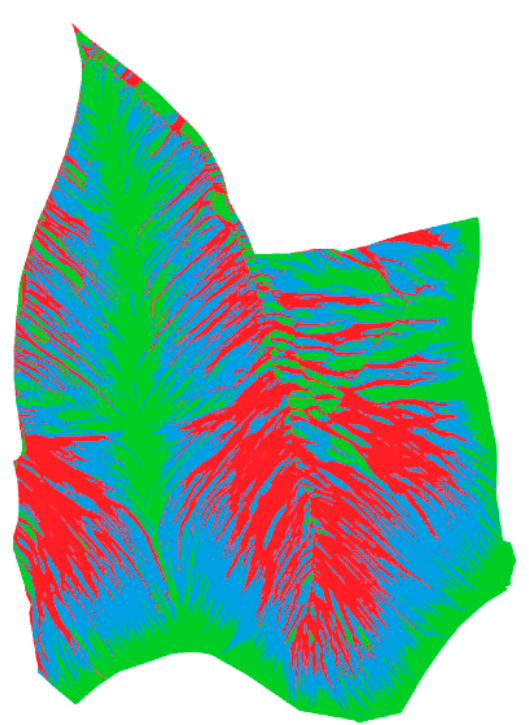

flow accumulation

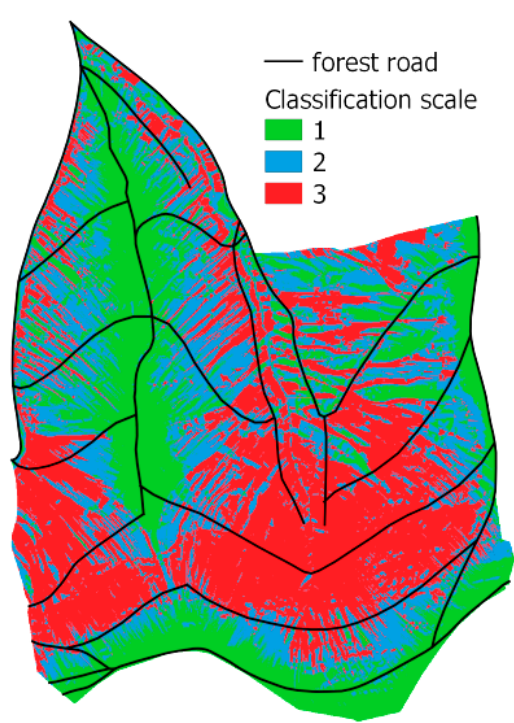

result of analysis

Figure 2 Slope and runoff concentration analyses with the forest road network design

A new proposal for the optimization of the forest road network was accomplished on the basis of the analysis and delimitation of the study area into zones according to suitability for the design and construction of roads. The creation of the new proposal was driven by the desire to place the road network predominantly in the zones 1 and 2 . The other goal of road network optimization was to decrease the average real skidding distance and to increase the efficiency $U$ concurrently. The network was extended by $3.235 \mathrm{~m}$ of new roads situated with respect to the terrain configuration and erosion prevention. The new roads almost follow the contours, however they are designed in optimal longitudinal slope for well structure drainage (Fig. 3). The designed solution supposed the elimination of $299 \mathrm{~m}$ of roads traced out inappropriately and the recultivation of the affected forest land.

The actual and designed forest road network parameters are summarized in Table2. The new road layout caused the decrease of all types of skidding distances. The real skidding distance Ds decreased by $51 \%$ to the value of $72 \mathrm{~m}$. In addition, the road network efficiency increased by $14 \%$.

Lotfalian, Zadeh and Hosseini (2011) investigated the skidding and theoretic distances in Chafrood forest using the same methodology developed by Beneš, however they focused on the estimation correction factor of mean skidding distance. The parameters of the designed optimal

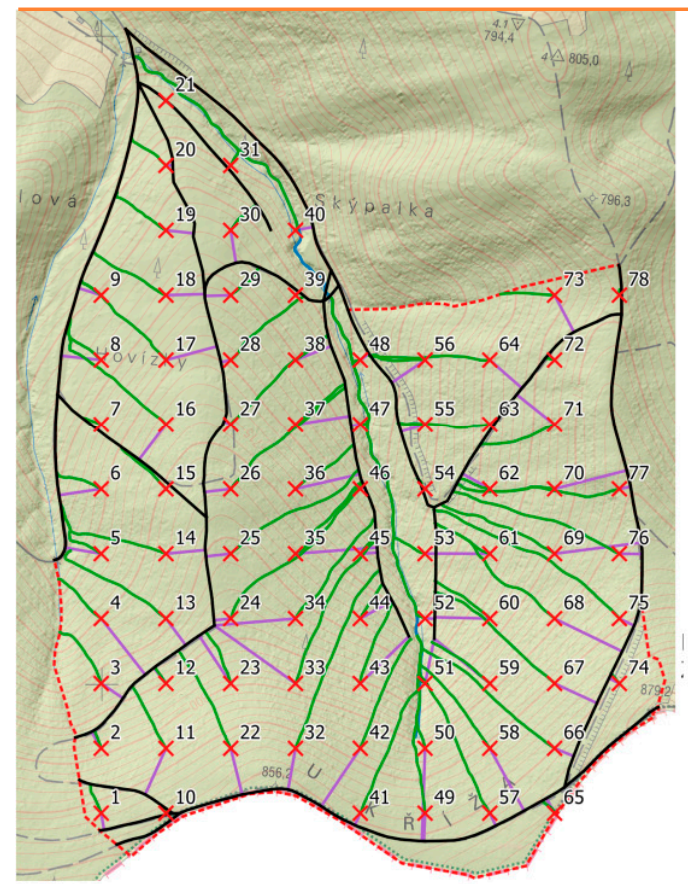

actual forest road network

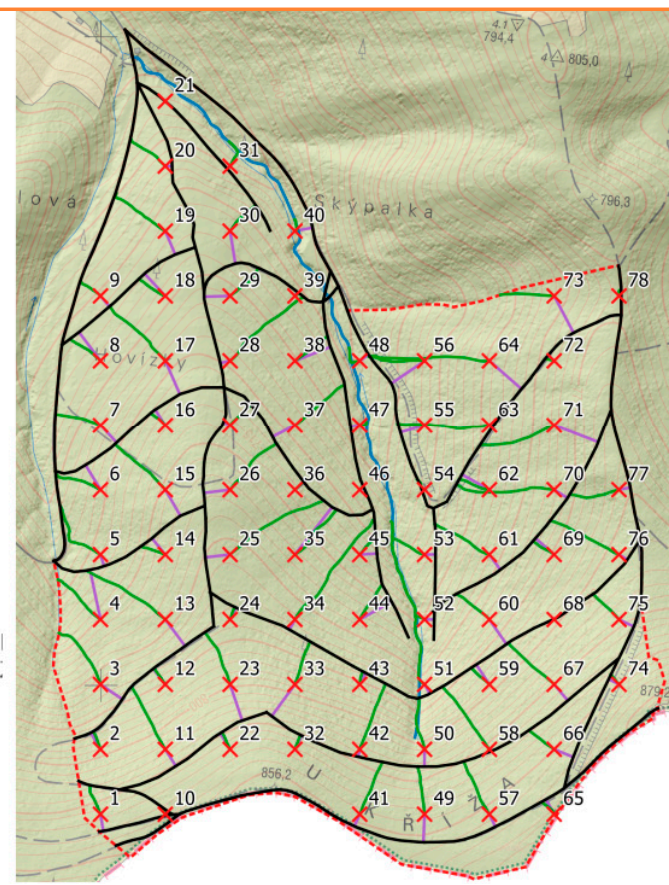

designed forest road network
- forest road

$\times \quad$ ha grid

- Dg ... geometric distance

D Ds ... skidding distance

- stream

area boundary

Base map:

ZM ČR 1:10 000

\section{$1: 10000$}

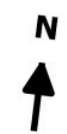

$0 \quad 100 \quad 200 \quad 300 \quad 400 \mathrm{~m}$

Figure 3 The actual and designed forest road network 
Table 2 Road network parameters

\begin{tabular}{|l||c|c|c|c|c|c|}
\hline & $\boldsymbol{D}(\mathbf{m})$ & $\boldsymbol{H}\left(\mathbf{m} \cdot \mathbf{h a}{ }^{-1}\right)$ & $\boldsymbol{D}_{\boldsymbol{s}} \boldsymbol{\varnothing}(\mathbf{m})$ & $\boldsymbol{D}_{\mathbf{g}} \boldsymbol{\varnothing}(\mathbf{m})$ & $\boldsymbol{D}_{\boldsymbol{t}}(\mathbf{m})$ & $\boldsymbol{U}(\%)$ \\
\hline Actual & 6,090 & 75 & 147 & 53 & 33 & 63 \\
\hline Design & 9,026 & 111 & 72 & 31 & 22 & 72 \\
\hline Difference & $+48.0 \%$ & $+48.0 \%$ & $-51.0 \%$ & $-41.5 \%$ & $-33.0 \%$ & $+14.0 \%$ \\
\hline
\end{tabular}

forest road network in the Beskydy Mountains reach slightly different parameters due to the special demands on the forest management, but reaching high value of the road network efficiency of $72 \%$.

\section{Conclusion}

The benefit of the forest road network optimization using slope analysis and runoff concentration is to reduce the negative impacts of the roads on the surrounding environment. A significant reduction in skidding distances was achieved by supplementing the road network in the area of interest, which will allow a successive transformation to a selective forest management.

\section{References}

AMMON, W. 2009. Výběrný princip v lesním hospodářství. 1. vyd. Zlín : Lesnická práce s.r.o., 2009, 157 s. ISBN 978-80-87154-25-0.

BENEŠ, J. 1973. Vliv tvaru terénu na dopravní zpřístupnění lesa. In Lesnictví, roč. 19, 1973, č. 6, s. 479 - 492.

BENEŠ, J. 1986. The preconditions of opening up of the forests. Folia Universitatis Agriculturae. Brno : VŠZ, 1986.

HRŮZA, P. - PELIKÁN, P. - HEMR, O. 2019. Comparison of the current solution of the single trail Moravský kras centre with a selected centre abroad. In Public recreation and landscape protection - with sense hand in hand...: Conference proceeding, $1^{\text {st }}$ ed., Brno : MZLU, 2019, pp. 62-66. ISBN 978-80-7509-659-3.

KREŠL, J. 1990. Kriteria řešení lesní dopravní sítě z hlediska vodohospodářských požadavků. Závěrečná zpráva SVE VI-6-7/0402, Brno : VŠZ, 1990, $37 \mathrm{~s}$.

LOTFALIAN, M. - ZADEH, E. H. - HOSSEINI, S. A. 2011. Calculating the correction factor of skidding distance based on forest road network. In Journal of forest science, vol. 57, 2011, no. 11, pp. 467-471

NOVO, A. et al. 2019. Automatic detection of forest-road distances to improve clearing operations in road management. International Archives of the Photogrammetry, 2019. Remote Sensing and Spatial Information Sciences - ISPRS Archives, vol. XLII-2/W13, pp. 1083-1088.

POLANSKÝ, B. 1966. Pěstění lesů. 1. vyd. Praha : SZN, 1966, 514 s.

SIMANOV, V. - MACKŮ, J. - POPELKA, J. 1993. Nový návrh terénní klasifikace a technologické typizace. In Lesnictví, roč. 39, 1993, č. 10, s. 422-428.

SKOUPIL, J. 2006. Optimalizace tvorby a rekonstrukce lesní dopravní sítě z hlediska integrovaných funkcí lesa. Disertační práce : Ústav tvorby a ochrany krajiny LDF MZLU, Brno, 2006, 100 s. 